\title{
SENHORAS DA CASA: UMA VISÃO SOBRE A IMPORTÂNCIA DO FEMININO NA SOCIEDADE EGÍPCIA DA XVIII DINASTIA
}

\section{HOUSEWIFES: AN INSIGHT INTO THE IMPORTANCE OF WOMEN IN THE EGYPTIAN SOCIETY OF XVIII DYNASTY}

Priscila Scoville

Resumo: Quando pensamos no Egito Antigo, comumente o imaginamos como uma região governada por homens, que recebem o título de faraó e exercem o poder sem questionamentos. É verdade que, para aquela sociedade, um dos deveres dos homens era o ato de conduzir, o que inclui o de governar; contudo, muitas mulheres tiveram papéis importantes no governo egípcio. Este trabalho visa mostrar as funções e a influência feminina aristocrática na religião e na política do Egito durante a XVIII dinastia, a partir do exemplo de algumas rainhas. Com isso, espera-se que o leitor supere a noção de que as mulheres foram passivas nesse período.

Palavras chave: Egito Antigo; XVIII dinastia; Rainhas; Mulheres.

Abstract: When people think about Ancient Egypt, usually they imagine it as a region ruled by men, who receive the title of pharaoh and exercise power without question. It's true that for this society one of the duties of the men was the act of leading, which includes the act of ruling; however, many women had important roles in the Egyptian government. Thus, this paper aims to show the aristocratic female functions and the influence on religion and politics of Egypt during the XVIII dynasty, using the example of some queens. Therewith, it's hoped that the reader overcome the notion that women were passive in this period. Keywords: Ancient Egypt; XVIII dynasty; Queens; Women.

\footnotetext{
${ }^{1}$ Estudante do sétimo período do curso de História Memória e Imagem da UFPR. Orientada pelo Prof. Dr. Renan Frighetto. Currículo lattes: //buscatextual.cnpq.br/buscatextual/visualizacv.do?id=K4029757J7.
} 
As relações de gênero no Egito Antigo são muito debatidas. Alguns pesquisadores afirmam que a sociedade era machista, enquanto outros afirmam que havia igualdade entre os $\operatorname{sexos}^{2}$. Contudo, antes de discutir essas questões, devemos ter em mente que o debate sobre gênero, como o conhecemos hoje ${ }^{3}$, é extremamente recente, não havendo

${ }^{2}$ Essa discussão pode ser encontrada em livros como ARNOLD, Dorothea (org). The Royal Women of Amarna: Images of Beauty from Ancient Egypt. New York: Distributed by Happy N. Abrams, Inc, The metropolitan Museum of Art, 1996; BAKOS, Margaret M. Fatos e Mitos do Antigo Egito. Porto Alegre: EDIPUCRS, 2009; GRAVES-BROWN, Carolyn. Dancing for Hathor. Women in Ancient Egypt. London: Continuum, 2010; SOUZA, Anna Cristina Ferreira de. Nefertiti, sacerdotisa, deusa e faraó. Rio de Janeiro: Madras, 2012; WATTERSON, Barbara. Women in Ancient Egypt. Stroud: Amberley, 2013; e no artigo GRALHA, Julio. Senhora da Casa, Deusa, Faraó: as várias imagens da mulher egípcia. Site NetHistória. Brasília, set. 2003. Sessão Ensaios. Disponível em:

http://www.nethistoria.com.br/secao/ensaios/363/senhora da_casa_deusa_farao as varias imagens da mulher egipcia/ acesso em: 17 mai. 2014.

${ }^{3}$ De acordo com SILVA, Kalina Vanderlei \& SILVA, Maciel Henrique. Dicionário de conceitos históricos. São Paulo: Contexto, 2009, o debate sobre gênero se inicia na década de 1960, com os movimentos feministas, contudo, somente nos anos 1980, quando as discussões historiográficas se afastam da política, o termo é elaborado para manter-se aparentemente neutro e desvinculado da ideologia feminista. O conceito de gênero associa, todavia, a teoria e a política, estando, normalmente, associado ao estudo das relações entre homens e mulheres e como essas relações são organizadas em diferentes sociedades, épocas e culturas, pelas ciências humanas. Tal estudo ajudou a despertar o interesse da historiografia em compreender a multiplicidade de identidades femininas ao longo da história. É importante frisar, porém, que há uma distinção entre a esfera biológica e a esfera social e cultural, que é a identidade de gênero. No campo historiográfico, os estudos de gênero visam contrapor a visão de diferenças biológicas ou sexuais, entre homens e mulheres, que acaba naturalizando a dominação masculina, isto é, o conceito pretende superar vi- 
qualquer tipo de discussão nesse sentido durante o Egito Antigo. Portanto, não devemos pensar as relações entre homens e mulheres egípcios com os conceitos modernos que carregamos, isto é, devemos esquecer os debates feministas dos anos 1960 e considerar o que era natural para aquele povo.

Homens e mulheres desempenhavam papéis na sociedade egípcia, com deveres próprios, isto é, as responsabilidades femininas e masculinas não se misturavam. De fato, havia uma certa equiparidade entre os sexos para garantir a maat $^{4}$ (SOUZA, 2012: 38). Isso não significa que as mulheres eram inferiores ou superiores aos homens, mas, tampouco, eram semelhantes.

Por um lado, temos uma sociedade dispare, na medida em que separa os ofícios por gênero; por outro, os ofícios se completam, ou seja, os deveres masculinos dependiam dos femininos e vice-e-versa. Isso talvez aconteça devido ao conceito de dualidade trazido por suas crenças, uma vez que a sociedade se organizou apoiada na religião e que, para agradar aos deuses, todos deviam cumprir suas obrigações. Deste modo, nenhum ofício era menosprezado por ser ligado a um sexo específico, sugerindo que nenhum gênero se sobrepunha ao outro e que homens e mulheres não eram rivais.

sões e estereotipadas em relação às condutas das pessoas, e outra é a forma como, no cotidiano, essas pessoas percebem o corpo.

${ }^{4}$ Maat é o nome da deusa egípcia, filha de Rá, responsável por manter a justiça, verdade e ordem do universo. Seu nome era usado como um termo cujo significado era o mesmo que as suas responsabilidades. Para fins didáticos, neste trabalho iremos utilizar "maat" (em minúsculo e itálico) para nos referirmos ao conceito, e "Maat" (normal, iniciando em maiúsculo) para a deusa. 
Cabia aos homens os ofícios ligados aos atos de conduzir (o que inclui governar), julgar e guerrear, enquanto a principal função das mulheres era gerar filhos (SOUZA, 2012: 38). Neste ponto, a nossa visão moderna iria nos fazer deduzir que, sim, a sociedade egípcia era machista, já que os cargos mais elevados estão ligados ao masculino. Contudo, para os egípcios a maternidade era algo extremamente importante, a ponto de dar às mães descontentes com o tratamento dado pelos filhos o direito de, na velhice, deserdá-los (WATTERSON, 2013: 36-39).

É o escriba do palácio de Ahmose-Nefertari que escreve as "Instruções de Any”, que são instruções de sabedoria, lírica amorosa e, por exemplo, ensinamentos sobre como escolher e conviver com a mulher ${ }^{5}$. Essas "Instruções de Sabedoria" manifestam uma noção de sociedade regrada e perfeitamente organizada $^{6}$ e, por veicularem a ideia, ajudavam a institucionalizar máximas. No que diz respeito às mulheres, é possível termos uma noção do papel social que eram induzidas a desempenhar e o modo como o homem deveria se relacionar com elas (BAKOS, 2009: 45). No caso das "Instruções de Any", o escriba faz quatro recomendações: o homem deveria casar-se jovem para ter muitos filhos, deveria ter

${ }^{5}$ As Instruções de Any, porém, não abordam somente aspectos das relações amorosos e convivência com o feminino, mencionando, também, os modos de se portar em outras instancias, como no culto religioso, por exemplo.

${ }^{6}$ É importante lembrar que a sociedade não era necessariamente do modo descrito nesses textos, isto é, o que está sendo escrito é idealizado e faltava naquele povo e precisava ser inserido na mentalidade dos egípcios. Era uma forma de induzir as pessoas a agir da forma dita perfeita. Isso pode ser visto em LICHTHEIM, Miriam. Ancient Egyptian Literature: The New Kingdom, vol II. University of California Press, 2006, pp. 135-146. 
cuidado com mulheres estranhas em sua cidade, pois elas poderiam ser casadas e tentar seduzi-lo, não controlar a mulher dentro de casa, quando ela é eficiente, e devia ter amor a sua mãe, sendo as duas últimas expressas na seguinte instrução:

Retribua em dobro a comida que sua mãe the deu,

Sustente-a como ela sustentou você;

Ela teve em você um fardo pesado, mas ela não o abandonou.

Quando alguns meses depois de você ter nascido,

Ela ainda o tinha como sua canga.

Seus seios em sua boca por três anos.

Como você crescia seu excremento ficava nojento,

Mas ela não se enojava, dizendo: "O que podemos fazer?"

Quando ela mandou você à escola

E você foi ensinado a ler e a escrever,

Ela ficou vigiando você diariamente,

Com pão e cerveja na sua casa.

Quando você como um jovem tomar uma mulher.

E você se estabelecer na sua casa.

Preste atenção no seu produto,

Faça-o crescer como fez sua mãe.

Não lhe dê motivo para amaldiçoa-lo

Para que ela não tenha que levantar suas mãos para Deus,

E ele tenha que a ouvir chorar. (BAKOS, 2009: 49-51).

Uma vez casadas, as mulheres recebiam o título de $N b t \operatorname{Pr}^{7}$ (senhora da casa) e deveriam prezar pela harmonia e estabilidade do lar, pelo controle das servas e gerar e cuidar da educação dos filhos. Deste modo, as egípcias esperavam engravidar logo depois do casamento, e,

\footnotetext{
${ }^{7}$ Em SILVA, Thaís R. "Lugar de mulher não é na cozinha” Rearticulando gênero e alimentação no Egito antigo. NEARCO - Revista Eletrônica de Antiguidade, Ano VII, Número I, 2014, pp. 374 - 375, a autora argumenta que o título - status - nbt pr é garantido, mas não limitado, pelo casamento e, aparentemente, era conferido somente às mulheres de elite.
} 
para isso, faziam preces às Deusas Hathor, que ouviria as súplicas, Bastet, que amadrinhava a casa, e Tauret, deusa da fertilidade, felicidade e protetora das mães; e usavam de amuletos que garantiriam a fertilidade, como um cinto contendo um símbolo semelhante a uma vulva ${ }^{8}$ (GRAVES-BROWN, 2010: 60-61).

A mulher, destarte, não era privada de uma vida independente de seu marido. Elas tinham direitos que foram se perdendo com as conquistas grega, romana, árabe e cristã e que somente no mundo contemporâneo as mulheres, de algumas culturas, conseguiram reconquistar. As egípcias poderiam adotar crianças em seu nome, caso desejassem, pedir divórcio, prestar testemunho, receber heranças, possuir e administrar bens e determinar com quem estes ficariam depois de sua morte (WATTERSON, 2013: 31-39). Em todas as instancias da vida, as mulheres eram tratadas como os homens, podendo andar livremente pelas ruas sem a necessidade de véus cobrindo a cabeça ou o rosto (BAKOS, 2009: 60). Além disso, apesar de raramente serem alfabetizadas, elas poderiam ser trabalhadoras e exercer atividades importantes dentro de templos, como musicistas, dançarinas e acrobatas em cerimônias religiosas, e, também, eram comumente requisitadas para a coleta e extração de essências das flores.

8 Em, SILVA, J. G. Espaço das representações sexuais e eróticas no Egito Antigo. Espacialidades, v. 5, p. 71-98, 2012, a autora afirma que no Papiro Erótico de Turim podemos notar que as mulheres "usam duas peças que fazem referência à questão da sexualidade, a peruca, e o cinto de conchas. Ambos são elementos da sexualidade e fertilidade egípcio" 
Na religião, o grande número de deusas nos sugere que a presença do feminino era importante para o funcionamento do mundo. Essas divindades são representadas em várias esferas cultuais, possuindo posição elevada, como, por exemplo, Ísis e Néftis, que sempre se mostram presentes no Julgamento de Osíris (SOUZA, 2012: 59). Outro exemplo é Hathor, que possuía diversas atribuições; era a deusa da dança, música e amor (HAT, 2005: 61-65), mas também era a filha do deus Sol e a deusa das terras estrangeiras. Por isso, foi bastante adorada desde o Reino Médio, quando recebeu um templo no Sinai, até o Reino Novo, quando Ramsés II aumentou, consideravelmente, o Templo de Hathor em Dendera, que continuou crescendo durante o domínio romano (SHAW \& NICHOLSON, 1995: 84-85). Um terceiro exemplo, que não podemos deixar de comentar é a deusa Maat, protetora da justiça e responsável pela ordem do universo. Sua importância era tanta que seu nome era utilizado como o termo que se refere às coisas que a deusa protegia. Mesmo durante o governo de Akhenaton, falou-se muito na maat, que garante o equilíbrio das coisas do mundo. Segundo a crença, era com uma pena das asas de Maat que se pesava o coração do morto para saber se ele havia sido bom, justo e verdadeiro em vida.

A importância de Maat aparece, então, nas esferas cultuais funerárias e da ordem do universo, contudo, esta última se expressa, também, no modo como o rei deveria agir. Segundo Cyril Aldred,

o peso necessariamente grande da tradição formava o corpo de ma'at e assim, só ocasionalmente o faraó podia jactar-se de tomar 
decisões diferentes das dos seus antepassados, desde os tempos primitivos, quando os deuses dominavam (ALDRED, 1966: 164).

Isso significa que o rei deveria seguir a tradição para que a ordem do universo fosse mantida, o que explica a visão de um Egito homogêneo e constante que temos nos dias atuais ${ }^{9}$.

Segundo Souza, o feminino está separado em três princípios básicos no Egito faraônico. O primeiro é o da fertilidade da terra, seguido da maternidade e a relação com seus filhos (vinculando-se a terra já fertilizada) e, por fim, as faces positivas e negativas da maturidade, sendo a "velha sábia" ou a "velha bruxa". Esses três princípios, nos povos antigos, são, normalmente, representados por diferentes deusas, contudo, na Grécia e no Egito todas essas características poderiam ser encontradas na personalidade das deusas Hécade e Hathor, respectivamente (SOUZA, 2012: 61).

Apesar das funções políticas não serem ligadas ao sexo feminino, muitas mulheres da XVIII dinastia conquistaram posições privilegiadas. Havia nesse período uma tendência matriarcal, as rainhas e mulheres da nobreza desempenharam papeis de grande importância e influência. Como consequência disso, ao menos em parte, temos a elevação de Hatshepsut a faraó (SOUZA, 2012: 39).

Ahhotep (c. 1590-1530 AEC) é a primeira rainha a receber destaque na XVIII dinastia. Ela era mãe de Ahmose, o faraó que expulsou os

\footnotetext{
${ }^{9}$ Sabemos, porém, que o Egito Antigo passou por diversos conflitos e mudanças, tanto internas quanto externas, que afetaram o modo de viver daquele povo.
} 
hicsos e iniciou a dinastia, foi, então, a última rainha da XVII dinastia. Durante os últimos anos do Segundo Período Intermediário, iniciou-se uma tentativa de reestruturação do Egito, por parte dos tebanos, que queriam expulsar a dinastia mais influente da região, a hicsa. Quando Ahmose ascendeu ao trono, sua pouca idade levou Ahhotep a assumir a corregência. A rainha conseguiu manter a ordem e encaminhar a expulsão definitiva dos hicsos e a pacificação do Egito (ALDRED, 1966: 134), sendo mais tarde, homenageada pelo filho por esses atos. Em uma estela do $18^{\circ}$ ano de reinado de Ahmose, o rei homenageia sua mãe, dando a ela títulos que implicam que ela, de fato, governou a região. De acordo com Betsy M. Bryan, Ahhotep não foi bem sucedida nas questões militares, mas conseguiu preservar a linhagem da dinastia incipiente, ganhando o respeito das tropas locais e dos nobres, num momento de bastante tensão no Egito. Ela continuou na função de "mãe do rei" também no governo de Amenhotep I, e em sua tumba, além do título já citado, recebeu o de "irmã do rei", "filha do rei" e "grande esposa real" (BRYAN, 2003: 218).

A próxima rainha a ganhar posição de destaque foi AhmoseNefertari (c. 1570-1505 AEC), que era esposa de Ahmose e possivelmente filha de Ahhotep. Seu nome aparece pela primeira vez na "estela da doação" feita por Ahmose, onde é descrita como a "filha do rei", "irmã do rei", "grande esposa real", "esposa do deus Amon" e "Senhora do Alto e Baixo Egito". A rainha operava independentemente de seu marido na construção de monumentos e nas operações de cargos religiosos (BRYAN, 2013: 219). Ahmose, ainda, compra para sua esposa o 
título de "segundo profeta de Amon", cargo que ela manteve até o reinado de Tothmés I e que só seria assumido posteriormente por homens. A posição conquistada pela rainha não era apenas religiosa, ela exercia poder político, uma vez que essas coisas não se separavam no Egito Antigo - o que explica o fato de Ahmose-Nefertari ter usado mais frequentemente o título de "esposa do deus Amon" que o de "grande esposa real".

Outra personagem importante foi Satamon, filha de Amenhotep I. Ela não chegou a se tornar rainha, mas recebeu o título de "esposa do deus Amon" e foi venerada, juntamente com Merytamon (possível irmã e consorte de Amenhotep I) como membro da família de AhmoseNefertari até o período ramessida, inclusive em cenas que deificavam a família real (BRYAN, 2003: 220).

Em seguida, Hatshepsut (c. 1479-1457 AEC) aparece com tal força que sua tumba foi construída no Vale dos Reis (tumba KV20) como governante. Filha de Tothmés I e Ahmose, assumiu o título de "esposa do deus Amon" após a morte de Ahmose-Nefertari. Hatshepsut casou-se com Tothmés II, mas não teve filhos homens para assumir o poder. Por isso, sua filha, Nefrura, deveria casar-se com um filho de Tothmés II e uma esposa secundária, Tothmés III. Como Tothmés III ainda era muito jovem quando Tothmés II morreu, Hatshepsut assumiu a regência. Acredita-se que a rainha via-se como herdeira de Tothmés I, antes mesmo de seu pai morrer. Isso significa que o período de governo de Tothmés II, talvez, tenha se aplicado ao regime de Hatshepsut, bem como o do filho do rei. É possível, também, que Hatshepsut tenha se 
aproveitado da participação econômica e da aproximação com a família de Ahmose-Nefertari (talvez pelo próprio sangue, através de Ahmose ${ }^{10}$ ) que o título de "esposa do deus Amon" lhe dava para manter sua regência similar à de suas predecessoras, Ahhotep e Ahmose-Nefertari (BRYAN, 2013: 228). Por outro lado, como a função de governar cabia aos homens a rainha precisou vincular-se a posição de faraó usando trajes masculinos, mostrando-se descendente direta dos deuses (SOUZA, 2012: 30) e enfatizando a linhagem sanguínea, com os títulos de "filha do rei", "irmã do rei", "esposa do deus" e "grande esposa real". Além disso, em textos e cenas de Hatshepsut em Deir el-Bahri, afirmase que Tothmés I havia anunciado Hatshepsut como sua herdeira e que Ahmose foi escolhida por Amon para gerar um governante divino. A lenda sobre o nascimento de Hatshepsut afirma que Amon teria se transformado em Tothmés I por uma noite, para possuir o corpo da rainha. Tal encontro gerou uma filha: Hatshepsut (HUSAIN, 2004: 196-207). Com a teogamia, Hatshepsut tornara-se a filha legítima do deus e seu caráter divino justificava a tomada do poder.

\footnotetext{
${ }^{10}$ Não se sabe ao certo quais são as origens de Ahmose. Essa rainha recebe o título de "irmã do rei" e "grande esposa real", podendo ser, então, irmã de Tothmés I, já que lhe faltava o título de "fillha do rei". Contudo, o nome de Ahmose sugere que ela pertencia à família de Amenhotep I, talvez por parte de Ahmose-ankh, irmão mais velho de Amenhotep I que morreu antes de assumir o trono.
} 
Uma vez conferido um nome de trono, Maatkara, e começado a se transformar publicamente em um rei, Hatshepsut teve apenas um exemplo para seguir: Sobekkara Sobekneferu ${ }^{11}$.

Diferentemente do governo de seus sucessores, marcados pela expansão militar, o regime de Hatshepsut mostrou-se mais atento na construção de grandes monumentos e foi uma das primeiras forças egípcias a fazer tratados com os povos asiáticos. A rainha inaugurou monumentos muito superiores aos de seus antecessores e em uma vasta região, construindo especialmente em: Kom Ombo, Hierakopolis, Elkab, Amarnt, Elefantina; e na Núbia, em Qasr Ibrim, Sai, Semna, Faras, Quban e Buhen. A região de Mênfis também pode ter recebido a atenção de Hatshepsut como governante. Além das minas de Hatnub, não há registros de reis da XVIII dinastia que tenham construído no Médio Egito ${ }^{12}$, antes de Hatshepsut e sua longa inscrição em Speos Artemidos, que documenta que ela foi a primeira a restaurar templos na região desde as guerras contra os hicsos. (BRYAN, 2013: 229-230). Contudo, nenhuma região recebeu mais atenção que Tebas. A rainha fez grandes doações ao clero de Amon e, assim, o templo de Amon em Karnak cresceu, ainda mais, em seu regime. Hatshepsut é a responsável pela construção do oitavo pilone, o novo portal sul de entrada, por exemplo. A rainha desejava construir uma nova entrada principal para o templo de Amon e ligálo ao templo de Mut (GRAVES-BROWN, 2010: 152).

\footnotetext{
${ }^{11}$ Sobekkara Sobekneferu era uma mulher que governou nos fins da XII dinastia

${ }^{12} \mathrm{O}$ Médio Egito é a região que se situa entre o Alto e o Baixo Egito, nos arredores de Mênfis.
} 
Durante o governo de Hatshepsut o Egito encontrou-se em paz novamente: os hicsos haviam sido expulsos e a última revolta na Núbia fora contida por seu marido, Tothmés II. Deste modo, a rainha pôde explorar os recursos naturais do Egito e da Núbia: o ouro vinha abundantemente dos desertos do leste e do sul, as minas de pedras preciosas estavam em operação, em Gebel el-Silsila buscava-se arenito, o cedro era importado do oriente e o ébano era trazido da África (possivelmente de Punt).

Anos mais tarde, Tiye (c. 1398-1338 AEC) casou-se com Amenhotep III, o que causou uma interrupção na linhagem real. A rainha era filha de Yuya, sumo sacerdote de Min e, mais tarde, chefe da cavalaria, e Tuya, superintendente do Harém de Min, de Akhmin, e de Amon, de Tebas, e da alta hierarquia do culto de Ahmose-Nefertari. (SOUZA, 2012: 84-85). Era importante que classe mais nobre aceitasse Tiye como a "grande esposa real", mas, apesar de ser filha de cortesãos de alta posição e de grande influência local, em comparação ao rei, Tiye era apenas uma plebéia.

Contudo, Tiye exerceu grande influência no governo de seu marido e, depois, no de seu filho, Amenhotep IV/Akhenaton, tendo grande importância política fora das fronteiras egípcias. Em Sedeinga, na Núbia, a rainha recebeu um templo, durante o regime de Amenhotep III, onde foi deificada e adorada. Ainda sob o governo de Amenhotep III, Tiye tornou-se parte do programa solar. A rainha era o olho de Rá no Sudão e, provavelmente, aderiu ao culto de Nebmaatra para voltar ao Egito e restaura a ordem do mundo, bem como Maat (BRYAN, 2013: 
259). Além disso, algumas das Cartas de Amarna ${ }^{13}$ indicam a influência de Tiye. Um bom exemplo é a que recebeu do rei de Mitani, Tushratta $(\mathrm{EA} 26)^{14}$.

\begin{abstract}
Diga a Tiye, senhora do Egito: De Tushratta, rei de Mitani. Para mim, tudo vai bem. Que tudo vá bem para você. Para a sua família, para seu filho, que tudo vá bem. Para Tadu-Heba, minha filha, sua nora, que tudo vá bem. Para os seus países, para suas tropas, e para qualquer outra coisa que te pertence, que tudo vá muito, muito bem.

Você é a que sabe que eu sempre mostrei amor por Mimmureya ${ }^{15}$, seu marido, e que Mimmureya, seu marido, por outro lado, sempre mostrou amor por mim. E as coisas que eu escreveria e diria para Mimmureya, seu marido, e as coisas que Mimmureya, seu marido, escreveria e diria para mim, você, Keliya, e Mane sabem. Mas você é a única, por outro lado, que é a que sabe muito melhor todas as outras coisas que nós diríamos um para outro. Ninguém mais as sabe tão bem.
\end{abstract}

${ }^{13}$ As Cartas de Amarna são cerca de 350 cartas encontradas na cidade de Akhetaten (atual Tel El-Amarna), em 1887. Segundo MORAN, William. The Amarna Letters. Baltimore: The John Hopkins University Press, 1992, essas correspondências podem ter sido, inicialmente, encontradas em expedições clandestinas, mas logo enviaram-se expedições em busca delas. Em 1891-92, Flinder Petrie encontrou mais 22 fragmentos, que foram enviados a Oxford. Escritas em meados do século XIV AEC, estas cartas possuem inscrições em cuneiforme (escrita diplomática da época) com acordos entre o Egito e os povos vizinhos, independentes ou vassalos. Em 1907, J. A. Knudtzon organizouas cronológica e geograficamente, em um sistema utilizado até hoje com a sigla "EA". Somente em 1992, William L. Moran, da Universidade de Harvard, publicou estas cartas em inglês. Este fato possibilitou o trabalho de outros pesquisadores, uma vez que, até então, a única forma de saber o conteúdo das cartas era conhecendo o cuneiforme. Para a realização deste estudo, foi lida a versão de William L. Moran, da carta em inglês.

${ }^{14}$ A carta EA26 atualmente se encontra no British Museum, sob o número de catálogo E29794.

${ }^{15}$ Nome dado a Amenhotep III nessa série de correspondências. 
E agora, você mesma disse para Keliya, "Diga para o seu senhor: Mimmureya, meu marido, sempre mostrou amor por seu pai, e mantinha-o por você, ele não esqueceu o amor por seu pai, e ele não cortou as embaixadas que ele costumava enviar, um após o outro. E agora você é quem não pode esquecer seu amor por Mimmureya, seu irmão. Aumente isso para Naphurreya ${ }^{16} e$ mantenha isso por ele. Você deve continuar a enviar embaixadas de alegria, uma após a outra. Não as corte".

Eu não vou esquecer o amor por Mimmureya, seu marido. Mais do que nunca antes, neste momento, eu mostro dez vezes - muito, muito - mais amor para Naphurreya, seu filho. Você sabe as palavras de Mimmureya, seu marido, mas você não mandou todas as saudações-presente que seu marido ordenou para serem enviadas. Eu pedi para seu marido estátuas de ouro maciço, dizendo "Que meu irmão envie para mim, como minhas saudaçõespresente, estátuas de ouro sólido fundido e ouro e genuína lápislazúli". Mas agora Naphurreya, seu filho, substituiu por estátuas de madeira. Como ouro sendo pó no país de seu filho, por que elas [estátuas de ouro] tem sido motivo de tanta aflição para seu filho que ele não me enviou elas para mim? Além disso, eu pedi [...] para me dá-las. Isso é amor? Eu tenho dito, "Naphurreya, meu irmão, irá me tratar dez vezes melhor que seu pai me tratou”. Mas agora ele não me enviou nem mesmo o que seu pai era acostumado a me enviar.

Por que você não expôs para Naphurreya as palavras que você mesma, com a sua própria boca, disse para mim? Se você não expuser para ele, e você continuar em silêncio, alguém mais pode saber? Faça Naphurreya me enviar estátuas de ouro maciço! Ele não deve me causar aflição mais, nem [...]. Faça-o tratar comigo dez vezes melhor que seu pai tratou, com amor e evidencia de estima.

Que seus próprios mensageiros vão regularmente com mensagens de Naphurreya, com 5 [...]para Yuni, minha esposa, e que os mensageiros de Yuni, minha esposa, vão regularmente para você.

${ }^{16}$ Nome dado a Amenhotep IV/Akhenaton. 
Eu com isso envio sua saudação-presente [x] recipientes para perfume cheios de "óleo doce" e um conjunto de pedras incrustadas em ouro. ${ }^{17}$

Pela carta podemos concluir que a rainha esteve bastante consciente das políticas externas do Egito, visto que, ao estar descontente com as ações de Akhenaton, Tushratta cobra intervenções diretamente a Tiye.

Tiye, ainda, foi retratada por seu marido em diversas estátuas colossais, junto a ele, e aparece como uma esfinge esmagando os inimigos (SOUZA, 2012: 86). Quando pensamos nas regras de proporções da arte egípcia, em que o tamanho da pessoa é proporcional ao de sua importância (por isso o rei deve ser sempre representado maior que os demais), fica interessante notar que em várias dessas estátuas Tiye aparece representada com o mesmo tamanho que o seu marido.

Durante o governo de Akhenaton, Tiye aparece em cenas domésticas, sendo que a mais famosa é um banquete em que ela e o casal real aparecem. O governo de Akhenaton ficou famoso por, entre muitas outras coisas, sua arte diferenciada. Predominavam-se cenas cotidianas, mostrando a intimidade da família real, por isso, a presença de Tiye nessas imagens ilustra a importância que a rainha teve, não só no governo de Amenhotep III, mas, também, no de Akhenaton.

Se por um lado Hatshepsut expandiu o culto de Amon, Nefertiti (c. 1380 - 1345 AEC) casou-se com Akhenaton, o faraó que abandonou

\footnotetext{
${ }^{17}$ Tradução própria, do inglês. Texto em inglês retirado de: MORAN, William. The Amarna Letters. Baltimore: The John Hopkins University Press, 1992, pp. 84-85. Original em cuneiforme em: catálogo E29794, British Museum.
} 
o culto de Amon para adorar Aton. Essa rainha começou a popularizarse em 2003 quando acreditou-se ter encontrado sua múmia, mas que, por fim, acabou-se descobrindo que era a múmia de Tiye (SOUZA, 2012: 86-87). A imagem de Nefertiti, em especial seu busto, difundiu-se nas massas, sendo representada em objetos e vestuário e proclamada, na literatura, como a mulher mais bonita da história, como seu nome sugere $^{18}$. Um papiro da XVIII Dinastia descrevia Nefertiti da seguinte forma:

Com seu esbelto colo e peito radiante tem por cabelos verdadeiro lápis-lazúli; seus braços superam os da deusa do amor e seus dedos são como cálices de lótus. Ela 'a de nobres andares' quando pisa a terra faz com que todos se voltem para contemplála e é como se contemplassem aquela que é a Única...

Pouco se sabe sobre suas origens, mas atualmente, uma das teorias mais suportadas afirma que a rainha era filha de Ay, provável irmão de Tiye e, portanto, Nefertiti seria prima de Akhenaton. Independentemente de suas origens, Nefertiti teve uma importância inquestionável mesmo antes das mudanças propostas por seu marido.

Nefertiti nunca recebeu o título de "esposa do deus", uma vez que esse remetia a Amon. Contudo, recebeu uma posição equivalente como sacerdotisa do culto diário, sendo retratada, em Karnak, usando as mesmas roupas usadas pelas “esposas do deus Amon”. Em Karnak, a rainha aparece fazendo oferendas a Aton sem a presença de Akhenaton. Embo-

${ }^{18}$ Nefertiti em egípcio significa "a bela chegou". 
ra as rainhas sejam representadas, normalmente, agindo passivamente no governo de seus maridos, Nefertiti é representada em talatats de Amarna massacrando inimigos, num modo tipicamente masculino, talvez seguindo a tradição de mostrar Tiye como uma esfinge (GRAVESBROWN, 2010: 156).

No início do reinado de Akhenaton, Nefertiti usava insígnias comuns às rainhas da XVIII dinastia, como a coroa de plumas, porém, não usou o toucado de abutre, uma vez que fazia referência a deusa Mut, esposa do deus Amon (SOUZA, 2012: 89). Entretanto, no quinto ano de reinado, Amenhotep IV mudou seu nome para Akhenaton, o que significaria "o espírito atuante de Aton", deixando de fazer referência a Amon, e Nefertiti trocou seu nome para Nefernefruaton-Nefertiti ${ }^{19} \mathrm{e}$ substituiu o toucado de plumas com o disco solar pela sua famosa coroa azul. Tal coroa não é vista em nenhuma outra rainha, o que confere um caráter único a Nefertiti.

Por volta do décimo quarto ano de reinado ${ }^{20}$ de Akhenaton as referências a Nefertiti desaparecem das fontes, fazendo com que muitos assumam a sua morte, apesar de não haver evidências disso, o que, por sua vez, gera diversas teorias. Alguns acreditam que Nefertiti teria assumido a corregência do Egito sob o nome de Semenkhare, o faraó que governou durante os dois últimos anos de reinado de Akhenaton e pos-

\footnotetext{
${ }^{19}$ Que significa, em egípcio, "belas são as belezas de Aton. A bela chegou”.

${ }^{20}$ Não podemos afirmar com certeza a data do "desaparecimento" de Nefertiti. O recorte temporal varia entre os anos 12 e 14 de reinado de Akhenaton, variando de acordo com o pesquisador. Para mais TYLDESLEY, Joyce. Nefertiti. Penguin Books, 2005, p. 150- 180.
} 
suía Nefernefrutaten como prenome ${ }^{21}$. Contudo, nada pode ser afirmado por enquanto.

Monumentos que representam mulheres da família real nas regiões de fronteira são comuns durante a XVIII dinastia, possivelmente para seguir uma tradição mais antiga. Podemos encontrar representações desse tipo no Sinai e na Núbia, da primeira até a quarta catarata nos reinos Médio e Novo. Talvez esses monumentos visem ligar à deusa Hathor essas rainhas e princesas, que governavam como a filha do deus sol para proteger o pai nas terras estrangeiras (BRYAN, 2013: 220).

A sociedade estava organizada para que os homens fossem os responsáveis pela parte administrativa do Egito, contudo, as rainhas mostraram-se bastante influentes no fortalecimento do culto de Amon e, depois, no de Aton, com Nefertiti, além de serem ativas politicamente, como no exemplo de Tiye. Essas mulheres participaram da organização da sociedade, sendo reconhecidas inclusive posteriormente. Foram deificadas e adoradas ao longo do Reino Novo. Nesse sentido, entretanto, Nefertiti mostrou-se como uma exceção, uma vez que seu marido foi banido ao esquecimento da história oficial, assim como seu culto a Aton. Nefertiti, por fazer parte disso, agindo a favor de seu marido, também teve seu nome e imagens apagadas de templos e estelas. Por outro lado, isso significa que Nefertiti agiu ativamente a ponto de dever ser banida quando o culto a Amon foi restaurado.

${ }^{21}$ Segundo SHAW, Ian \& NICHOLSON, Paul. British Museum Dictionary of Ancient Egypt. Londres: British Museum Press, 1995, p. 311, NefernefruatenSmenkhkara governou entre 1338 e 1336 AEC. 
É claro, porém, que esse breve estudo não pode abranger as mulheres em uma totalidade. Destarte, a partir desses exemplos, podemos afirmar que houve, de fato, uma forte tendência matriarcal durante a XVIII dinastia, conferindo às rainhas um papel importante nas questões políticas e religiosas do Egito.

\section{Referências Bibliográficas}

ALDRED, Cyril. Os Egípcios. Lisboa: Editorial Verbo, 1966.

ARNOLD, Dorothea (org). The Royal Women of Amarna: Images of Beauty from Ancient Egypt. New York: Distributed by Happy N. Abrams, Inc, The metropolitan Museum of Art, 1996.

BAKOS, Margaret M. Fatos e Mitos do Antigo Egito. Porto Alegre: EDIPUCRS, 2009.

BRYAN, Betsy M. The 18th dynasty before the Amarna Period (c. 1550- 1352 BC) IN: SHAW, Ian. The Oxford History of Ancient Egypt. New York: Oxford University Press, 2003, pp. 207- 264.

COHEN, Raymond \& WESTBROOK, Raymond (org). Amarna Diplomacy: the beginnings of international relations. Baltimore, The John Hopkins University Press, 2000

DODSON, Aidan. Amarna Sunset: Nefertiti, Tutankhamun, Ay, Horemheb, and the Egyptian Counter-Reformation. Cairo: The American University in Cairo Press, 2009.

DONADONI, Sergio (org). O Homem Egípcio. Lisboa: Editorial Presença, 1994.

GRALHA, Julio. Senhora da Casa, Deusa, Faraó: as várias imagens da mulher egípcia. Site NetHistória. Brasília, set. 2003. Sessão Ensaios. Disponível

em: http://www.nethistoria.com.br/secao/ensaios/363/senhora_da_casa_deus a farao as varias imagens da mulher egipcia/ Acesso em: 17 mai. 2014. 
GRAVES-BROWN, Carolyn. Dancing for Hathor. Women in Ancient Egypt. London: Continuum, 2010.

GRIMAL, Nicolas. História do Egito Antigo. Rio de Janeiro: Forense Universitária, 2012.

HAT, George. The Routledge Dictionary of Egyptian Gods and Goddesses. New York: Routledge, 2005.

LICHTHEIM, Miriam. Ancient Egyptian Literature: The New Kingdom, vol II. University of California Press, 2006.

MORAN, William. The Amarna Letters. Baltimore: The John Hopkins University Press, 1992

MURNANE, William J. (org). Texts from the Amarna Period in Egypt, Atlanta: Scholars Press, 1995.

SILVA, J. G. Espaço das representações sexuais e eróticas no Egito Antigo. Espacialidades, v. 5, p. 71-98, 2012.

SILVA, Kalina Vanderlei \& SILVA, Maciel Henrique. Dicionário de conceitos históricos. São Paulo: Contexto, 2009.

SILVA, Thaís R. "Lugar de mulher não é na cozinha” Rearticulando gênero e alimentação no Egito antigo. NEARCO - Revista Eletrônica de Antiguidade, Ano VII, Número I, p. 366 - 389, 2014.

SHAW, Ian \& NICHOLSON, Paul. British Museum Dictionary of Ancient Egypt. Londres: British Museum Press, 1995.

SOUZA, Anna Cristina Ferreira de. Nefertiti, sacerdotisa, deusa e faraó. Rio de Janeiro: Madras, 2012.

WATTERSON, Barbara. Women in Ancient Egypt. Stroud: Amberley, 2013. 